\title{
Golden parachutes: Changing the experience of unemployment for managers
}

\author{
Anya M. Johnson ${ }^{\text {a,* }}$, Paul R. Jackson ${ }^{\mathrm{b}}$ \\ a Australian School of Business, University of New South Wales, Australia \\ b Manchester Business School, The University of Manchester, UK
}

\section{A R T I C L E I N F O}

\section{Article history:}

Received 31 March 2011

\section{Keywords:}

Unemployment

Job loss

Psychological strain

Agency

Support

Financial strain

\begin{abstract}
A B S T R A C T
We examined the effect of career transition support and three other situational variables financial reserves, social inclusion, and a partner - on the psychological strain of unemployed managers. We extended the theories of unemployment by investigating the mechanisms by which these four situational variables affect psychological strain. After using qualitative research to explore managers' experiences during unemployment, we used the themes that emerged from this first study to conduct a survey on the unemployment experiences of 281 managers. Each of the situational variables protected unemployed managers from psychological strain through a different pathway. The pathways that emerged were agency, the emotions associated with loss, financial strain, and a positive emotional response. The research provides evidence of the utility of providing a 'golden parachute' and the additive effects of financial reserves and social inclusion. Evidence from the research also suggests that support programs for unemployed individuals should focus on enhancing agency and regulating emotions to assist with the transition into employment.
\end{abstract}

(c) 2011 Elsevier Inc. All rights reserved.

\section{Introduction}

The sudden spike of job losses throughout the developed economies, particularly within the ranks of middle management from relatively stable financial institutions, has been followed by a rise in unemployment in all sectors of the economy. This change raises the question, what do we know about the consequences of unemployment, the mechanisms that explain those consequences, and the utility of providing assistance? We need to dust the cobwebs off research on these topics, which proliferated when unemployment last dominated the headlines in the mid-1970s the early 1980s, and the early 1990s.

A recent meta-analysis (Paul \& Moser, 2009) examining the effect of unemployment on mental health across 237 crosssectional and 87 longitudinal studies provides convincing evidence that unemployment is psychologically damaging and suggests that psychological strain is the result of rather than the cause of unemployment. However, relatively little research has investigated managerial unemployment (with some exceptions: Fielden \& Davidson, 2001; Hartley, 1980; Kozlowski, Chao, Smith, \& Hedlund, 1993). Yet job loss among managers has become an inevitable part of the career cycle. In this study we extend our understanding of unemployment research by changing two key features: 1) the sample: managers who were laid off, and 2) the context: a 'golden parachute', consisting of a substantial financial payment and social and structural support through an ongoing career transition program. We expand on the implications of these features below.

Our overarching aim is to determine if situations protect individuals from psychological strain during major life events such as unemployment, and to uncover the mechanisms through which this buffer works. Career transition support, financial reserves, social inclusion, and having a partner are generally considered to be protective, but there is little research on whether these variables differentially affect the experience of unemployment to protect against psychological strain.

\footnotetext{
* Corresponding author at: School of Organisation and Management, Australian School of Business, UNSW, Sydney, 2052 Australia. Fax: + 61293136775.

E-mail address: anya.johnson@unsw.edu.au (A.M. Johnson).
} 
A.M. Johnson, P.R. Jackson / Journal of Vocational Behavior $x x x$ (2011) $x x x-x x x$

This paper consists of two studies. In study 1, we explore managers' unemployment to identify categories of experience and determine whether these categories map onto unemployment theory. In Study 2 we investigate whether these unemployment experiences are mechanisms through which situational factors influence psychological strain.

\section{Study 1: managers' experience of unemployment}

\section{Introduction}

In study 1 our aim was to map managers' experience of unemployment against existing theory to elaborate and clarify the theory and to determine whether it generalizes to managers. We do this by building a rich contextual picture of the experience and perceptions of unemployed managers who were being supported by career transition counseling. We used a qualitative approach to enable an understanding of dynamic processes, embedded in the context. This approach provides "not only the flexibility to explore the unexpected, but to see the unexpected" (Conger, 1998, p. 119).

A handful of theories that describe and explain why unemployment is psychologically damaging have dominated the literature. Jahoda (1982) distinguishes between manifest and latent benefits of working. The manifest purpose of employment is to earn money, however the latent consequences are also intrinsically beneficial. Job loss deprives individuals of key benefits associated with working, specifically, imposed structure, an enlarged scope of social contact and shared experiences, external goals and purpose, status, and activity. While Jahoda's theory is widely used and intuitively appealing, it may not provide a useful framework for understanding the experience of managers who have been laid off with a severance package. Not only do these managers have money (albeit time-limited), but they also have many latent features of working embedded in the career transition support: imposed structure, shared experiences with peers, goals, purpose and activity, and arguably some status from receiving the severance package. Based on Jahoda's theory, we expect these managers to be protected from the loss of the latent benefits of working.

Jahoda's model has not been without critics. Feather and Bond (1983) argue that not all jobs share these beneficial consequences equally and that highly skilled and varied work is at one end of a continuum with impoverished unemployment at the other. They argue that the study of unemployment is better served by job satisfaction and work design theory, with unemployment having a spectrum of latent functions of work. Unemployed managers with a severance package might be better represented at the middle of the continuum-better off than many unemployed people, but worse off than employed managers.

One example of this approach is Warr's (2007) nine-factor vitamin model, which explains variations in mental health for both employed and unemployed individuals. His model includes opportunity to use skills, employment commitment, opportunity for control, variety, and availability of money, in addition to situational factors such as employment rates. Warr (2007) argues that "not all unemployed people are equally unhappy.... An absence of financial pressure, good health and positive social support can decrease distress" (p. 70) as can low employment commitment and high unemployment rates. Jahoda (1982) argues that the latent by-products of any employment, versus their absence during unemployment, override individual differences in jobs. A repetitive, low-skilled job is better protection against psychological strain than no job. However, Jahoda's view does not take into account support programs for the unemployed, which may move an individual along the continuum. Warr's framework presents a more complex picture of interactions among factors which lead to positive or negative outcomes for unemployed individuals. Managers who are laid off with support have many protective factors, although high employment commitment and relatively low executive unemployment may be risk factors. For example, Karsten and Klaus (2006), in a metaanalysis, suggest that tension created by the imbalance between employment commitment and employment status also drives psychological strain during unemployment.

Fryer and McKenna (1987) suggest other limitations to Jahoda's theory. The results from a comparative study of two groups showed that workers who were temporarily 'rested' were significantly more active and had lower levels of psychological strain than the permanently laid-off workers. Fryer and McKenna's conclusion was that these differences were due to the workers' orientation to the future. Other qualitative research on unemployment (Fryer \& Payne, 1986) supports the proposition that the negative effects of unemployment are not due to the absence of the latent functions of work, but rather to the absence of its manifest purpose, money. These effects are not necessarily due to poverty, but because of the indirect limitations that financial constraint places on the future, or individual agency (personal control). Support for this theory comes from Price, Choi, and Vinokur (2002) who found that the loss of personal control during unemployment is "a pathway through which economic adversity is transformed into chronic problems of poor health and impaired role and emotional functioning" (p. 302). Restricted agency may be one mechanism that affects managers who have been laid off with a severance package. The loss of income does not create poverty for managers protected by a 'golden parachute', but psychological strain may occur because of the constraint on agency.

The transactional theory of stress has informed several models of the antecedents and mediators of psychological strain during unemployment (e.g., Mackay \& Cooper, 1987). In these models it is the imbalance between demands and the resources to cope with these demands (internal, external, actual and perceived) that create psychological strain. It is clear that the managers in our study had external resources (financial, social, and structural), but the psychological demands and resources are less clear. In this study we asked managers to describe the psychological challenges and benefits they experience during unemployment. Using grounded theory and theme analysis we generated a range of lived experiences, which we compare to existing theory. 
Method

\section{Participants}

The sample consisted of 36 senior managers attending the UK offices of a career transition company. All participants had been laid off by their previous employer, with a compensation package which included a payment of almost two years' salary (mean $=$ $£ 95,000$, US\$175,000) and career transition support. The career transition support included access to a well-resourced office, ongoing counseling to assist the managers with their emotional response to the job loss, and career counseling. The career counseling provided an opportunity for reflection on their values, strengths and interests; assistance in setting goals and planning for the future; job search skills training; and regular seminars and events. All the managers were male, with an average age of 45 years, previous income of $£ 53,000$ (US\$95,000), and 13 years' tenure. These managers were typical of all clients with two exceptions, longer tenure with their previous company and a higher severance payment.

\section{Procedure}

The researcher was introduced to all the managers in attendance at the career transition offices by the career transition counselor. The researcher described the purpose of the research to each of the managers (investigating manager's experience of unemployment) and then invited them to participate in an interview held in a private meeting room. All 36 managers in attendance over 8 days agreed to participate. Interviews were recorded with consent and transcribed. The focus of this study was the participants' response to the question, "What do you consider to be the worst/best aspects of being unemployed?"

For thematic analysis of the experience of unemployment, transcripts were analyzed by three independent researchers, using a grounded theory approach (Glaser \& Strauss, 1967; Henwood \& Pidgeon, 1992). Each researcher identified "thought units", which were then classified into themes. These themes were developed iteratively, moving between the data (thought units) and the emerging themes, until no further insights were added, reaching "theoretical saturation" (Glaser \& Strauss, 1967). Once no new themes emerged, themes were compared and a consensus reached on four overarching themes that best captured the thought units underlying meaning. The "thought units" were then reviewed to identify exemplars that best captured the meaning, and were particularly informative to bring the theme alive.

\section{Results and discussion}

Four broad categories of experience emerged from the thought units; three of which were negative and one positive (see Table 1). We called the first category loss, since it reflects an emotional response centered on what people lose when they are unemployed: social connections, self-esteem, status, sense of identity, purpose, and value. These elements feature within Jahoda's (1982) and Warr's (2007) models; however, there are two aspects of loss that don't feature in the traditional theoretical frameworks, rejection and bereavement, although there have been empirical studies that link unemployment or anticipated job loss to the grief cycle (Archer \& Rhodes, 1995; Blau, 2008; Brewington, Nassar-McMillan, Flowers, \& Furr, 2004). These may be particularly salient for managers who have high employment commitment and have been laid off after a long tenure. The second

Table 1

Categories of unemployment experience.

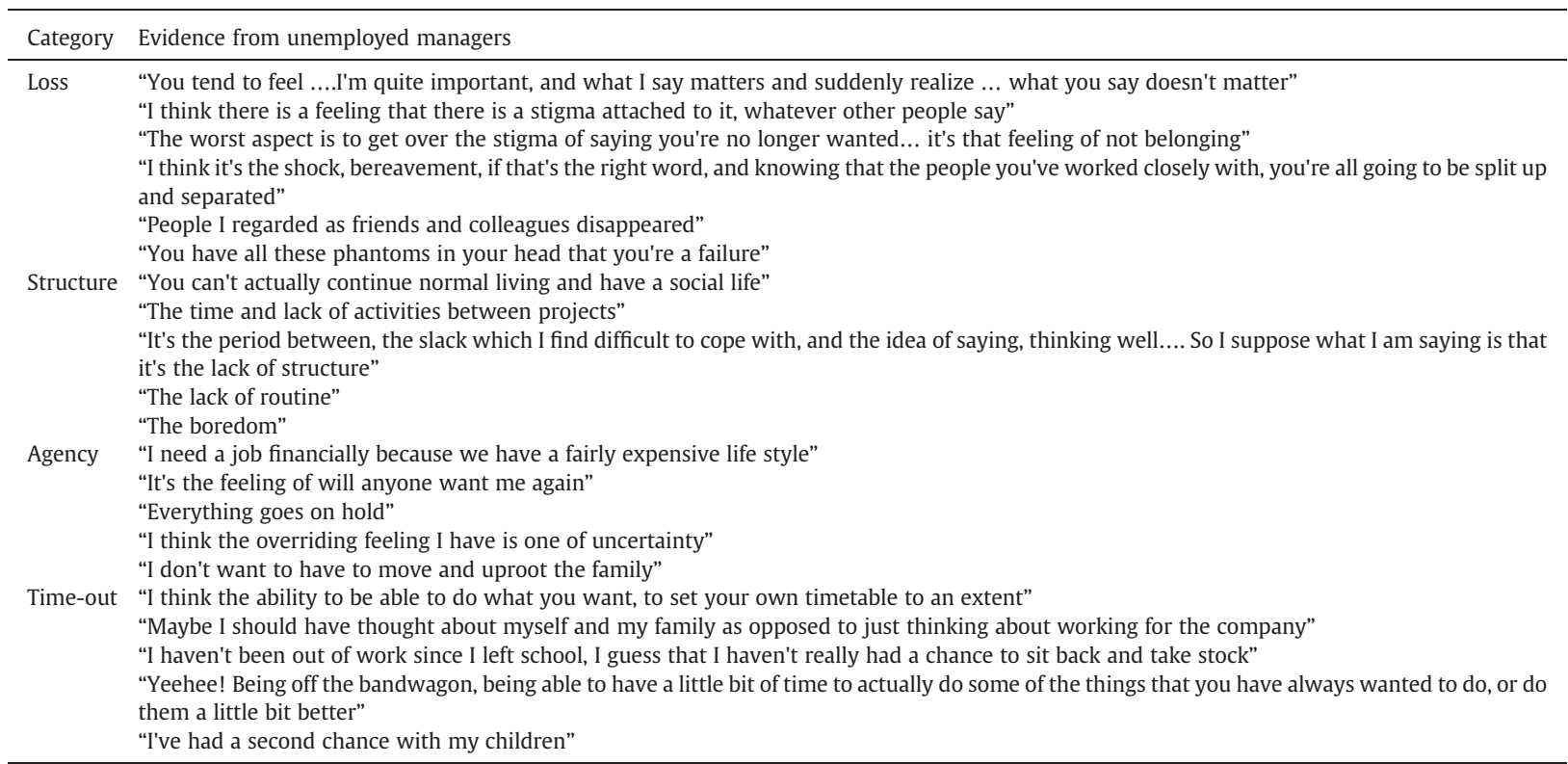


category is structure and draws together respondents' cognitions around time structure or its absence: boredom, routine, and the job search. The difficulty of dealing with what has been lost and the absence of structure are fundamental to Jahoda's latent benefits theory. The third category, agency, is also a cognitive construct, centered on individuals' future outlook and their loss of personal control, and includes themes such as inability to plan; not knowing if, when, or where re-employment will occur; and not having an income to support an established lifestyle. This category echoes Fryer's (1986) theory, that limitations on 'future orientation' are central to psychological strain during unemployment. Creed and Klisch (2005) also found that personal agency is an important mechanism in explaining psychological strain during unemployment.

While the first three categories of experience overlap existing unemployment research, the final category, time-out, captures managers' accounts of the positive benefits of taking 'time-out': freedom, family time, reflection, and rest. Positive perceptions of unemployment have received relatively little attention in the literature. Positive perceptions may be present in our participants because positive experiences are unique to supported unemployed managers, or these perceptions may be an artifact of the interview which primed managers to describe positive aspects of unemployment. In either case, we should be asking whether supported managers are more likely to have a positive experience and whether this is a mechanism through which career transition support protects managers from psychological strain.

Overall the themes suggest that existing theory, even when developed from research on blue-collar or youth unemployment, does provide some insight into the experience of unemployment for managers. However this research does not provide strong support for one theory over another. Rather this research suggests that combining or integrating theoretical perspectives may provide greater insight into unemployment. In addition, this research highlights some previously neglected areas of unemployment theory, specifically the opportunity for 'time-out' and the experience of bereavement and rejection. This qualitative research lays the foundation for Study 2, which investigates whether these themes are pathways through which career transition support and other situational variables protect unemployed managers from psychological strain.

\section{Study 2: golden parachutes: do they make a difference?}

\section{Introduction}

There is a long tradition in the literature of identifying interventions and situational protective factors that influence psychological strain during unemployment. These studies can be divided into three areas: research on the effect of support programs, financial variables, and social support. Prior to investigating these situational variables during unemployment our aim was to confirm that the empirical evidence from other studies, predominantly with young people (Jackson, Stafford, Banks, \& Warr, 1983; Winefield, Winefield, Tiggemann, \& Goldney, 1991) and blue-collar workers (Warr, Jackson, \& Banks, 1988), generalize to managers. Unemployment has traditionally been considered a universally difficult experience and recent reviews (e.g., Paul \& Moser, 2009), strongly support this assumption. This research tests this assumption with senior managers.

H1. There will be an effect of unemployment on psychological strain, such that unemployed managers will experience higher psychological strain than re-employed managers.

Next we describe why we expect situational factors to relate to psychological strain. Then we consider the mediating role of the categories of experience derived from Study 1.

\section{Career transition support programs}

Studies of the impact of short-term support programs for unemployed individuals have shown increased job search activity, decreased psychological strain, and increased re-employment (for example, Vinokur \& Schul, 1997; Vuori \& Silvonen, 2005). However, these studies have investigated either young or long-term unemployed people; only a few studies provide evidence that support programs for managers also reduce psychological strain (Joseph \& Greenberg, 2001; Mallinckrodt \& Fretz, 1988). Based on these studies we would expect unemployed managers with career transition support to experience lower levels of psychological strain than managers without this support. This leads to our second hypothesis:

H2a. There will be an effect of career transition support on psychological strain, such that unemployed managers who are supported will experience lower psychological strain than unemployed managers with no support.

What is less well established is why support programs have their effect. There is evidence that when support ceases, there is a resumption of pre-program levels of psychological strain. For example Creed, Hicks, and Machin (1998) found that unemployed participants did not maintain improvements in psychological well-being three months after completing a training and support program. The concurrent effects of the program in Creed, Hicks and Machins research might equally be explained by the latent benefits model (Jahoda, 1982), Fryer's (1986) agency theory or Warr's (2007) vitamin model. These programs are likely to replace latent benefits of work, since they incorporate features of work design and encourage individuals to be active and goal driven, and these effects may not be sustained after program completion. Without better understanding the mechanisms driving the reduction in psychological strain, it is difficult to design effective programs or sustaining change.

If career transition support is effective in reducing psychological strain, then it should modify the experience of unemployment, which in turn reduces psychological strain. The mechanisms we identified in Study 1 may explain why psychological strain is reduced, specifically that career transition support reduces the negative emotions associated with loss as well as the cognitive 
challenges associated with lack of structure and reduced agency or sense of control over the future, and increases the positive experience or opportunity for 'time out'. Specifically we expected:

H2b. Loss, agency, structure and 'time-out' will mediate the effect of career transition support on psychological strain.

\section{Financial reserves and financial strain}

One factor that complicates the investigation of the effect of career transition support on psychological strain is that these support programs are always accompanied by a severance payment. This introduces a second situational variable, as unemployed managers, whether provided with career transition support or not, will vary in the financial reserves they have to live off. Financial reserves are also likely to influence managers' experience of unemployment and feed into psychological strain. The third research question, therefore, was the extent to which having a financial cushion protects managers from psychological strain.

The impact of financial hardship or strain on psychological strain during unemployment has been relatively well documented in the literature. Price (1992) and Price, van Ryn, and Vinokur (1992) found that unemployed individuals who were most at risk were those experiencing high levels of financial hardship. Mallinckrodt and Fretz (1988) found financial concerns to be one factor that significantly predicted a number of stress symptoms in unemployed professionals over 40. Rowley and Feather (1987) found the same relationship irrespective of age. Kessler, Turner, and House (1988), using path analysis, found financial strain accounts for the largest proportion of the effects of unemployment on psychological strain. More recently, longitudinal studies of unemployed individuals also found financial strain to be a powerful predictor of psychological strain, over time (Price et al., 2002; Vuori \& Silvonen, 2005). This leads to our third hypothesis:

H3a. There will be an effect of financial reserves on psychological strain, such that unemployed managers who have higher reserves will experience lower psychological strain than unemployed managers with lower reserves.

Most studies mentioned above have included either a measure of perceived financial strain or an objective indicator of financial hardship. Very few studies have included more than one measure or attempted to tease out the relative influence of different types of financial constructs on psychological strain during unemployment. One exception is Rantakeisu and Jonsson (2003), who found a strong positive relationship between perceived economic concern and psychological strain and a significant but weaker relationship between economic security and psychological strain, suggesting both play a role.

From this literature it would seem that both the actual lack of money and financial worries are important contributors to psychological strain. However the pathways through which financial circumstances affect psychological strain are less clear. Based on previous research, an important mediator is likely to be worrying about money or perceived financial strain. However the lack of money has also been implicated in constraining agency (through limiting options available for action), which is also a potential pathway through which unemployment affects psychological strain (Fryer, 1986). Finally, it is also likely that a lack of financial reserves will reduce the opportunity to enjoy the benefits that a period of unemployment may present; therefore 'time-out' may be another pathway through which financial reserves influence psychological strain. This leads to the second part of the third hypothesis:

H3b. Agency, financial strain, and 'time-out' will mediate the effects of financial reserves on psychological strain.

\section{Social resources}

There is strong empirical evidence that social resources are important in protecting individuals during unemployment (Bolton \& Oatley, 1987; Gore, 1978; Jackson, 1988; Latack, Kinicki, \& Prussia, 1995; Warr et al., 1988). There is some evidence that unemployed managers have higher levels of resources and support than blue-collar workers (Atkinson, Leim, \& Leim, 1986; Mallinckrodt \& Bennett, 1992). However unemployed managers do experience reduced social contact and increased loneliness and isolation, and this has been shown to exacerbate psychological strain (Fielden \& Davidson, 2001). What is less clear is which types of social resources are most protective and the mechanisms through which these resources reduce psychological strain.

Cohen and Wills (1985) argued that it is important to distinguish between structural measures of social support or resources (which describe the existence of relationships) and the extent to which these resources provide particular functions, for example emotional or instrumental support. In this research we focused on structural social resources or an individual's embeddedness in his or her community. The extent to which managers are involved with or attend group activities (regardless of their purpose) is one indicator of their social connectedness or inclusion during unemployment and may be a factor that protects managers from psychological strain. This leads to our fourth hypothesis:

H4a. There will be an effect of social inclusion on psychological strain, such that unemployed managers who have higher levels of social inclusion will experience lower psychological strain than unemployed managers with lower levels of social inclusion.

Jahoda (1982) suggests that structure and shared experiences are important latent benefits of working, which may explain the protective qualities of social resources during unemployment. Fryer and Fagan (2003) argue that disempowerment or lower agency results from a lack of social resources. Drawing on these theories and contextual information from Study 1, we argue that the mechanisms which may help explain the effect of social inclusion are agency and structure. Managers who participate in ongoing group activities during unemployment may experience a greater sense of control over the future, which may in turn protect them from psychological strain. Managers who are embedded within social networks may have expectations about their activities and anticipated contact with others (in two weeks or three months) regardless of whether they have a new job may 
increase their sense of personal control over the future. In addition participation in regular activities may increase the perception of structure, which may also protect against psychological strain.

H4b. Agency and structure will mediate the effects of social inclusion on psychological strain.

At the most basic level, structural social resource has been conceptualized as the presence of a 'significant other'. Having a partner has been found to be protective for psychological strain in a sample of unemployed men (Price, 1992). Fielden and Davidson (2001) found that male managers identified their partners as their main source of emotional support. In addition Broman, Hamilton, Hoffman, and Mavaddat (1995) have found that marital status affects the responses of men to unemployment. This suggests that having a partner may provide some protection from psychological strain, particularly for men.

However other research (Vinokur \& van Ryn, 1993) suggests that close relationships can be socially undermining and have a significant negative impact on mental health, independent of any other source of social support. Being 'married' does not guarantee lower psychological strain, as it may also be a source of stress. While there have been mixed results in the literature (Ratcliff \& Bogdan, 1988; Starrin \& Larson, 1987), the weight of evidence suggests that being married or having a partner protects people from psychological strain during unemployment. This leads to our fifth hypothesis:

H5a. There will be an effect of partner on psychological strain, such that unemployed managers who have a partner will experience lower psychological strain than unemployed managers with no partner.

It is also important to determine the pathway through which having a partner has an effect. From a pragmatic perspective, one potential pathway is that the presence of a partner may reduce the financial strain the manager experiences. Having a partner, whether salaried or not, may provide additional options which will likely reduce worrying about money, which in turn may reduce psychological strain. However, without taking into account the quality of the relationship and the types of interactions (which are outside the scope of this research), it is unlikely that the presence of a partner will change other aspects of the experience of unemployment. This leads to the second part of our fifth hypothesis:

H5b. Financial strain will mediate the effects of partner on psychological strain.

In summary, Study 2 investigated the effect of situational variables on the psychological strain of managers during unemployment and specifically investigated the pathways through which these effects occurred (see Fig. 1).

\section{Method}

Study design and sample

This research used a cross-sectional survey design, recruiting participants in different situations (regarding employment status and career transition support) and taking advantage of naturally occurring variations in other situational variables (financial reserves and social support). The sample included 281 managers from the United Kingdom who were, or were until recently, unemployed. Managers were recruited from two sources: agencies in contact with unemployed managers in North West UK $(n=70)$ and a UK-wide career transition consultancy which provides customized long-term career transition support $(n=211)$. The career transition support was provided to managers as part of an employment severance package. The managers recruited

\begin{tabular}{c|c} 
Situational & $\begin{array}{c}\text { Mediators - 'experience of } \\
\text { unemployment' }\end{array}$
\end{tabular}

Outcome

$H 1, H 2 a, H 3 a, H 4 a, H 5 a$

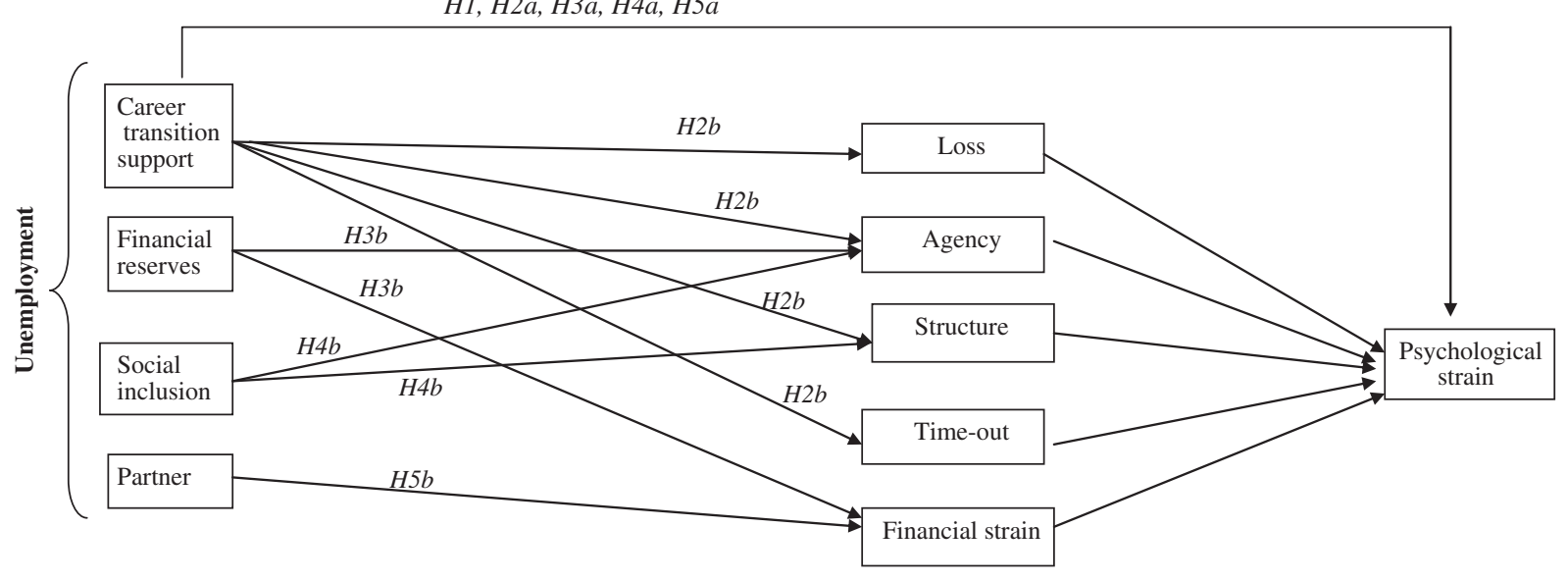

Fig. 1. Model of research hypotheses. 
through these two sources had similar demographic characteristics: $81 \%$ were male, $86 \%$ had a partner, and $72 \%$ were over 40 years old. The only demographic difference was previous salary, with the managers recruited through agencies earning a significantly lower pre-unemployment salary, which might be explained by location, as managers from the North West typically have lower salary levels than managers from the South East, where the majority of the career transition clients resided.

\section{Procedure}

A survey was sent to all individuals who were clients of the career transition consultancy within the previous year, with 211 surveys returned ( $52.1 \%$ response rate). We distributed surveys to managers not supported by a career transition program through 12 agencies who had contact with unemployed managers in North West UK. The agencies agreed to distribute the surveys on our behalf to unemployed managers in the sampling frame, which included no career transition support, a previous supervisory or managerial position, and a minimum annual salary. One hundred seventy-five surveys were provided to the agencies and 70 were returned by mail, representing a minimum response rate of $40 \%$.

\section{Measures}

We measured situational protective factors using the following constructs: Career transition support was coded as a dummy variable $(0=$ no career transition support, $1=$ career transition support). We measured the extent of financial reserves with a single item: "How much longer can your job search continue before you experience serious financial difficulties?" using a 6point scale from (1) up to one month to (6) over 18 months. The measure of social inclusion was adapted from Warr and Jackson (1985). Managers were asked to indicate their weekly or monthly involvement in any of the following group activities: business/professional associations, church/religious groups, social groups, sports groups, or 'other'. The final variable for the measure of social inclusion averaged the number of groups attended per week. Partner was measured by having participants indicate their marital or relationship status, which was dummy coded $(0=$ no partner, $1=$ partner $)$.

To measure the experience of unemployment mediators we created scales based on the categories derived from the qualitative analysis in Study 1. We asked participants, "Which of the following (if any) are you finding difficult?" and used a 5-point scale, with anchors (1) not difficult to (5) very difficult. Loss was assessed using five items: loss of status, social stigma, feeling of rejection, feeling of loss/bereavement and loss of self-esteem. Agency was assessed using four items: fear of long term unemployment, unable to plan for the future, loss of income, and disruption to normal family life. Structure was assessed with three items: lack of structure, unable to fill your time, and focus on job search only. Time-out was assessed with four items: more freedom, more family time, time to reflect and reassess, and being out of the rat race, using the stem, "Which of the following (if any) are you finding positive?" and a 5-point scale, with anchors (1) not positive to (5) very positive. Financial strain was measured using Warr and Jackson's (1985) single-item measure "To what extent have you had serious financial worries over the past month?" with a scale from (1) never to (5) all the time.

The dependent variable, context-free psychological strain, was assessed through the 12-item General Health Questionnaire (Banks et al., 1980; Goldberg, 1972), which has been widely used in unemployment research. A 4-point scale was used, ranging from 0 to 3, with high scores indicating greater psychological strain. Alphas are reported in Table 2.

Table 2

Descriptive statistics, Chronbach alphas and bivariate correlations for unemployed managers $(n=171)$.

\begin{tabular}{|c|c|c|c|c|c|c|c|c|c|c|c|c|c|}
\hline Variables & $M$ & $s d$ & alpha & 1 & 2 & 3 & 4 & 5 & 6 & 7 & 8 & 9 & 10 \\
\hline \multicolumn{14}{|l|}{ Demographic } \\
\hline 1. Gender ${ }^{\mathrm{a}}$ & .81 & - & - & - & & & & & & & & & \\
\hline \multicolumn{14}{|l|}{ Situational } \\
\hline 2. CT support ${ }^{\mathrm{b}}$ & .69 & - & - & -.09 & - & & & & & & & & \\
\hline 3. Financial reserves ${ }^{c}$ & 3.98 & 1.54 & - & .12 & $.27^{* *}$ & - & & & & & & & \\
\hline 4. Social inclusion ${ }^{\mathrm{d}}$ & .87 & .89 & - & .11 & -.06 & .01 & - & & & & & & \\
\hline 5. Partner ${ }^{\mathrm{e}}$ & .82 & - & - & $.25^{* *}$ & .02 & .14 & .00 & - & & & & & \\
\hline \multicolumn{14}{|l|}{ Mediators } \\
\hline 6. Loss & 2.62 & 1.09 & .89 & $-.22^{* *}$ & $-.21^{* *}$ & $-.23^{* *}$ & -.02 & -.11 & - & & & & \\
\hline 7. Agency & 3.23 & 1.03 & .82 & -.10 & $-.33^{* *}$ & $-.49^{* *}$ & -.12 & -.06 & $.65^{* *}$ & - & & & \\
\hline 8. Structure & 2.36 & .95 & .72 & -.03 & -.05 & -.10 & -.09 & -.08 & $.54^{* *}$ & $.49^{* *}$ & -- & & \\
\hline 9. Time-out & 3.54 & 1.00 & .83 & -.09 & $.26^{* *}$ & $.24^{* *}$ & .11 & -.05 & $-.29^{* *}$ & $-.38^{* *}$ & $-.17^{*}$ & - & \\
\hline 10. Financial strain & 2.44 & 1.36 & - & -.08 & $-.39^{* *}$ & $-.59^{* *}$ & .01 & $-.21^{* *}$ & $.38^{* *}$ & $.64^{* *}$ & $.19^{*}$ & $-.31^{* *}$ & - \\
\hline \multicolumn{14}{|l|}{ Outcome } \\
\hline 11. Psychological strain & 16.09 & 7.40 & .91 & $-.22^{* *}$ & $-.26^{* *}$ & $-.37^{* *}$ & $-.13^{\dagger}$ & $-.14^{\dagger}$ & $.67^{* *}$ & $.74^{* *}$ & $.45^{* *}$ & $-.39^{* *}$ & $.53^{* *}$ \\
\hline
\end{tabular}

a $0=$ female, $1=$ male.

b $0=$ no career transition support, $1=$ career transition support

c $1=$ up to 1 months reserves to $6=$ over 18 months reserve.

d number of groups attending per week.

e $0=$ no partner, $1=$ partner.

** $p<.01$.

$* p<.05$.

$+p<.10$. 
Table 3

Multiple mediation model testing experience of unemployment variables as mediators of the situational variables on psychological strain

\begin{tabular}{|c|c|c|c|c|c|c|c|c|c|}
\hline Predictors & $\begin{array}{l}\text { Effect of IV on } \\
\text { mediator }(a)\end{array}$ & & $\begin{array}{l}\text { Unique effect of } \\
\text { mediator }(b)\end{array}$ & & $\begin{array}{l}\text { Individual indirect } \\
\text { effect }(a b)^{1}\end{array}$ & & $\begin{array}{l}\text { Direct effect } \\
\left(c^{\prime}\right)\end{array}$ & $\begin{array}{l}\text { Total } \\
\text { effect }(c)\end{array}$ & $\begin{array}{l}\text { Degree of } \\
\text { mediation }\end{array}$ \\
\hline \multicolumn{10}{|c|}{ Career transition support } \\
\hline Loss & $-.38^{*}$ & & $1.25^{*}$ & & $-.47^{*}$ & & -.22 & $-2.94^{* *}$ & Complete \\
\hline Agency & $-.45^{*}$ & & $3.12^{* *}$ & & $-1.41^{*}$ & & & & Complete \\
\hline Structure & -.07 & & $.80^{\dagger}$ & & -.06 & & & & None \\
\hline Time-out & $.35^{*}$ & & $-.75^{\dagger}$ & & $-.26^{\dagger}$ & & & & Complete \\
\hline Financial strain & $-.71^{* *}$ & & $.72^{\dagger}$ & & $-.51^{\dagger}$ & & & & Complete \\
\hline \multicolumn{10}{|l|}{ Financial Reserves } \\
\hline Loss & $-.10^{\dagger}$ & & $1.25^{*}$ & & $-.13^{*}$ & & .11 & $-1.38^{* *}$ & Complete \\
\hline Agency & $-.29^{* *}$ & & $3.12^{* *}$ & & $-.89^{*}$ & & & & Complete \\
\hline Structure & -.07 & & $.80^{\dagger}$ & & $-.05^{\dagger}$ & & & & None \\
\hline Time-out & $.13^{*}$ & & $-.75^{\dagger}$ & & $-.10^{\dagger}$ & & & & Complete \\
\hline Financial strain & $-.43^{* *}$ & & $.72^{\dagger}$ & & $-.31^{\dagger}$ & & & & Complete \\
\hline \multicolumn{10}{|c|}{ Social inclusion } \\
\hline Loss & -.04 & & $1.25^{*}$ & & -.05 & & -.51 & $-1.12^{*}$ & None \\
\hline Agency & $-.13^{\dagger}$ & & $3.12^{* *}$ & & $-.41^{*}$ & & & & Complete \\
\hline Structure & -.09 & & $.80^{\dagger}$ & & $-.07^{\dagger}$ & & & & None \\
\hline Time-out & $.14^{\dagger}$ & & $-.75^{\dagger}$ & & $-.10^{\dagger}$ & & & & Complete \\
\hline Financial strain & .03 & & $.72^{\dagger}$ & & .02 & & & & None \\
\hline \multicolumn{10}{|c|}{ Partner } \\
\hline Loss & -.10 & & $1.25^{*}$ & & -.12 & & -.48 & -.63 & None \\
\hline Agency & .10 & & $3.12^{* *}$ & & .32 & & & & None \\
\hline Structure & -.18 & & $.80^{\dagger}$ & & -.14 & & & & None \\
\hline Time-out & -.20 & & $-.75^{\dagger}$ & & .15 & & & & None \\
\hline Financial strain & $-.49^{*}$ & & $.72^{\dagger}$ & & $-.35^{\dagger}$ & & & & Partial \\
\hline $\begin{array}{l}\text { Overall Model } \\
\text { summary }\end{array}$ & & $\mathrm{R}^{2}=.61^{* *}$ & & $\operatorname{Adj} \mathrm{R}^{2}=.59^{* *}$ & & $\mathrm{~F}=25.53^{* *}$ & $(\mathrm{df}=10,160)$ & & \\
\hline
\end{tabular}

Note. $n=171$. Model controls for gender. Significance levels based on bootstrapping (5000) bias corrected and accelerated confidence intervals.

** $p<.01$.

$* p<.05$.

$+p<.10$.

\section{Analytical strategy}

To explore the mediation hypotheses we entered the experiences of unemployment measures as mediation variables in a multiple-mediation model, in which all five mediators were entered simultaneously and the additional situational variables and gender were entered as controls (Preacher \& Hayes, 2008). We used the bootstrapping method with bias-corrected and accelerated confidence intervals to estimate the indirect effects in the mediational analyses and to compare the effects of the mediators with one another. The bootstrapping method is more powerful than the Sobel test and the causal steps approach, and it makes no assumptions about the underlying shape of the sampling distribution of the indirect effect (Hayes, 2009). This method also eliminated problems associated with omitting mediators, which can lead to biased parameter estimates when testing the mediators with a series of simple mediation models (Judd \& Kenny, 1981; Preacher \& Hayes, 2008).

Results

To assess the construct validity, we used exploratory factor analysis (maximum likelihood with oblimin rotation) with the experience-of-unemployment items. There were four factors with eigenvalues above 1 and items loading on the appropriate scales. Thus, loss, agency, structure, and time-out were distinct from each other and internally consistent.

We first examined the effect of employment status on psychological strain, and hypothesis 1 was confirmed with significantly higher psychological strain for the unemployed group $(t=-3.89, p<.01$; mean scores for the unemployed and re-employed groups were $16.09, n=188$ and $11.69, n=51) .{ }^{1}$ Having established that unemployment is psychologically damaging for this sample, we used the unemployed group for tests of our remaining hypotheses. Means, standard deviations, Cronbach alpha coefficients of reliability, and intercorrelations among the study variables are shown in Table 2.

Hypotheses 2 to 5 refer to each of our situational variables and consist of two parts: a) the direct effect on psychological strain, and b) the mediating effect of the experience-of-unemployment variables. The results from the multiple mediation analysis used to test the hypotheses are presented in Table 3. Direct effects of each situational variable are reported in column 5, which shows a significant direct effect on psychological strain in the predicted direction for three of the four situational variables (career

1 There were no demographic differences between unemployed and re-employed managers. 
transition support $\beta_{\mathrm{c}}=-2.94, p<.05$; financial reserves $\beta_{\mathrm{c}}=-1.38, p<.001$; social inclusion $\beta_{\mathrm{c}}=-1.12, p<.05$; partner $\beta_{\mathrm{c}}=$ $-.63, p=n s)$. Hypotheses $2 \mathrm{a}$, 3a, and $4 \mathrm{a}$ were confirmed, while hypothesis $5 \mathrm{a}$ was not.

Part $b$ of each hypothesis concerns the mediating role of the experience-of-unemployment variables, and the findings related to the mediational tests are shown in columns $1-3$ of Table 3 . All significance levels are two tailed, however as our hypotheses are directional we have included significance levels of 0.1 as evidence of our hypotheses when in the predicted direction and in combination with results with stronger effects. With respect to career transition support (hypothesis $2 \mathrm{~b}$ ), the direct effect of career transition support was significantly reduced $\left(\beta_{\mathrm{c}^{\prime}}=-.22 \mathrm{~ns}\right)$ by the five experience-of-unemployment variables. Only three of the hypothesized mediators had significant indirect effects: loss ( $\left.a b \_l o s s=-.47, p<.05\right)$, agency (ab_agency $=-1.41, p<.05$ ), and time-out ( $a b_{-}$time-out $=-.26, p<.10$ ). Structure did not meet the criteria for mediation. In addition there was evidence that financial strain is also a mediator ( $a b_{-}$financial strain $=-.51, p<.10$ ), which was not anticipated. Hypothesis $2 \mathrm{~b}$ is thus partially confirmed.

Hypothesis $3 \mathrm{~b}$ was supported; the direct effect of financial reserves was significantly reduced ( $\beta_{\mathrm{c}^{\prime}}=.11 \mathrm{~ns}$ ) by the five experience-of-unemployment variables. However while both the hypothesized mediators had significant indirect effects, agency ( $a$ b_agency $=-.89, p<.05)$, and financial strain ( $a b \_$financial strain $\left.=-.31, p<.10\right)$, two other experience-of-unemployment variables which were not hypothesized also had significant indirect effects: loss ( $\left.a b \_l o s s=-.13, p<.05\right)$, and time-out ( $a b \_t i m e-$ out $=-.10, p<.10$ ) and appear to also mediate financial reserves on psychological strain. (Structure also has an indirect effect $\left[a b \_\right.$structure $\left.=-.05, p<.10\right]-$ but there is no significant effect of financial reserves on structure so it does not meet the criteria for mediation.)

There was partial support for hypothesis $4 \mathrm{~b}$. The direct effect of social inclusion was significantly reduced $\left(\beta_{\mathrm{c}^{\prime}}=-.51 \mathrm{~ns}\right)$ by the five experience-of-unemployment variables. However only one of the two hypothesized mediators had a significant indirect effect, ( $a$ b_agency $=-41, p<.05$ ), and while structure also had an indirect effect ( $a b \_s t r u c t u r e=-.07, p<.10$ ), there is no significant effect of social inclusion on structure, so it does not meet the criteria for mediation. Time-out, which was not hypothesized, also had a significant indirect effect, (ab_time-out $=-.10, p<.10)$ and appears to mediate social inclusion on psychological strain.

There was partial support for hypothesis $5 \mathrm{~b}$; while the presence of a partner does not have a direct effect on psychological strain, there is some evidence of suppressed mediation through financial strain ( $a b \_$financial strain $=-.35, p<.10$ ). To determine if there is a third variable such as partner's job status or salary level that has suppressed the relationship, we conducted a post hoc examination. There is a negative partial correlation (controlling for sex) between partner being salaried (not salaried $=0, n=54$; salaried $=1, n=92)$ and GHQ $(r=-0.15)$, which suggests that managers with partners who are salaried have higher psychological strain than managers with partners who are not salaried, regardless of sex. (Partners who are job seeking, $n=13$, were excluded from this analysis.) However there is no partial correlation between having a salaried partner and financial strain $(r=.04 n s)$. This provides some insight into a possible confounding third variable that is influencing the relationship.

Overall the four situational variables, along with the five mediators, account for $59 \%$ of the variance in psychological strain, (Adj $\left.R^{2}=.59, p<.001\right)$ with career transition support having the greatest protective effect $(C=-2.94, p<.001$ ), followed by financial reserves $(C=-1.38, p<.001)$ and social inclusion $(C=-1.12, p<.05)$. As each situational factor takes into account overlapping variance with the other factors, each variable provides additive effects, so those most protected have all three situational variables.

\section{Discussion}

Overall we provide an extension to and test of some of the competing theories of the effects of unemployment on psychological strain. We also provide some insight into the generalizability of those theories to managers. The findings from Study 1 provide a parsimonious framework that reflects the experience of managers, combining elements of different unemployment theories. The findings from Study 2 provide evidence for the efficacy of career transition support, financial compensation, and social resources after a job loss. In addition Study 2, using the framework from Study 1, provides some insight into the mechanisms through which these variables affect psychological strain during unemployment.

In Study 1 we explored whether theories predominantly based on blue-collar and youth unemployment fit data from managers experiencing an involuntary job loss with a 'golden parachute'. Broadly the answer is yes, the experience is universal as there is considerable overlap between the themes identified and extant theories (Fryer, 1986; Jahoda, 1982; Warr, 2007). However there were some differences. The positive opportunities and a sense of loss and bereavement may be particularly salient to supported unemployed managers. These aspects of the experience of unemployment need to be added to the framework.

In Study 2 we found strong evidence that unemployment is associated with higher psychological strain for managers, and the comparison with recently re-employed managers provides evidence of the 'bounce back' that employment provides. These results and the large effect size are consistent with the literature (McKee-Ryan, Song, Wanberg, \& Kinicki, 2005; Murphy \& Athanasou, 1999; Paul \& Moser, 2009).

As hypothesized this effect is attenuated for managers who are provided with career transition support. This finding is consistent with previous research on other types of support programs (for example Vinokur \& Schul, 1997) and research on career transition programs such as Zikic and Klehe (2006) who found instrumental support from career transition counseling positively influenced career exploration which led to higher quality re-employment. The results of the multiple mediation analysis in this paper, controlling for other situational variables, provide some insight into the pathways through which support - whether it is institutional, individual, or financial - protects against psychological strain. 
Career transition support appears to protect unemployed managers from psychological strain by reducing the emotional demands or 'loss' associated with unemployment. While Jahoda (1982) includes status as one of the latent benefits of employment, emotional demands (as opposed to the emotional outcomes of psychological strain and depression) associated with unemployment receive little attention in unemployment theory. Based on the results from Study 1, we suggest that emotional demands are much broader than loss of status and include bereavement, loss of self-esteem, and feelings of rejection. The positive effect of career transition support may be due to counseling managers receive, although it may also occur through everyday interaction with others 'in the same boat'. However the latter explanation is less likely, as the managers without career transition support were interacting with others during their visits to agencies.

Career transition support also increases managers' sense of control or agency. Fryer (1986) argues that loss of income reduces agency; these results suggest that career transition support increases a sense of control over the future, over and above financial resources. Agency is an important mechanism through which career transition support protects against psychological strain and may be similar to mastery, which has also been found to be a mediator in an unemployment training program (Vinokur \& Schul, 1997). Creating a job search plan, setting goals, and regularly reviewing progress, all of which are part of career transition support, may be important in creating a sense of personal control over the future. It is also likely that agency is closely related to selfefficacy. "A sense of personal efficacy is the foundation of human agency. ... the core belief that one has the power to produce desired effects by one's actions, otherwise one has little incentive to act or to persevere in the face of difficulties" (Benight \& Bandura, 2004, p. 1131). Enhanced agency, underpinned by self-efficacy, appears to be a key mechanism through which career transition support protects managers from psychological strain during unemployment.

Career transition support also enables a positive appreciation of 'time-out' from the treadmill of corporate careers. This positive affective response, which is protective against psychological strain, may be stimulated through managers reviewing values, strengths and skills as well as setting new career and life goals. Fryer and Payne (1986) also found that individuals who were proactive and attempted to change the environment to suit their needs - for example, becoming involved in a voluntary activity were more resilient than individuals who were not active. One possible explanation for this is Fredrickson's (1998) broaden-andbuild theory, which suggests that individuals with positive affect or mood are more likely to engage in activities and craft a role for themselves, opening up possibilities for positive experiences; negative affect leads individuals to resist new experiences and turn inwards, focusing on their immediate environment (i.e., tunnel vision) rather than exploring opportunities (Broadbent, 1971). This finding also has parallels with Vinokur and Schul (1997) concept of inoculation against setbacks.

Interestingly, financial strain also mediates the effect of career transition support on psychological strain. On the surface this is unsurprising, as career transition support is accompanied by a severance package which provides a financial cushion, which should reduce financial strain. However, this mediation occurs when controlling for financial reserves, suggesting an effect unique to career transition support. This may be due to a spill-over effect from agency and positive affect which reduces financial worry. Also of interest is that structure is not a mechanism through which career transition support protects against psychological strain. This is surprising as lack of structure is frequently cited as key to explaining psychological strain (Jahoda, 1982) and is 'accepted wisdom' in unemployment counseling. However these results suggest that focusing on the affective response and enhanced agency and self-efficacy is more important than 'filling time'.

The pattern of mediation for financial reserves on psychological strain is identical to the pattern for career transition support, when controlling for career transition support (and sex, social inclusion, and having a partner). This suggests that financial reserves reduce the emotions associated with loss, enhance a sense of control, increase positive experiences, and reduce financial worries. While the pattern is the same, the effect sizes are reduced, suggesting that the dose is lower. From a practical perspective, providing financial compensation for job loss cushions the effects on psychological strain, but not to the same extent as career transition support.

Financial reserves had a direct effect on psychological strain, which challenges Jahoda's (1982) theory that it is not the loss of the manifest purpose of work-money-that creates psychological strain. The mediated effect through agency lends support to Fryer's (1986) theory and suggests that having financial resources enables an enhanced sense of agency or personal control over the future. Financial reserves also reduced the emotions associated with loss which mediated psychological strain. Financial reserves are also mediated by financial strain which supports previous research (Price et al., 2002; Vuori \& Silvonen, 2005), which found that financial strain drives psychological strain. However by separating financial reserves from perceived financial strain, the causal pathway becomes clearer and provides support for Rantakeisu and Jonsson's (2003) finding that economic security had a weaker impact than economic concern on psychological strain.

Our results add to the weight of evidence that social resources are protective during unemployment. We ask whether individual support matters when career transition support is available, and whether the type and source of support matter, as suggested by previous research. The results suggest a mixed picture. Social inclusion or regular group involvement was protective, and agency does appear to mediate the relationship. This is in line with Benight and Bandura's (2004) argument that social resources are "more than just a protective cushion against environmental onslaughts" (p. 1134). They argue that social support enables self-efficacy or agency through supporters modeling effective coping attitudes and skills and providing incentives for engagement in beneficial activities. Interestingly being actively involved in groups does not create structure, although there is an additional pathway through enhanced positive experiences.

The direction of these relationships is not as clear as in the case of career transition support and financial reserves. It is plausible that greater agency or more positive affect may increase social involvement, which in turn reduces psychological strain (Benight \& Bandura, 2004; Fredrickson, 1998), and as this study was cross-sectional, this rival explanation cannot be ruled out. In addition, this sample was predominantly male, and group activity has been shown to be more important for men during unemployment 
than for women (Stokes \& Levin, 1986), although this effect was observed when controlling for sex. The effect size for social inclusion is smaller, suggesting that social involvement alone would have a weaker effect on psychological strain, than in combination with career transition support and financial reserves.

Previous research has found that having a partner is generally protective, although the type and quality of the relationship have been moderators (Vinokur \& van Ryn, 1993; Westman, 2001). In our research the presence of a partner was not protective; however there appeared to be suppressed mediation, where a partner reduced financial strain, which in turn reduced psychological strain. This relationship may be suppressed because home-based partners may be more protective of psychological strain than working partners, offsetting the effect of a partner's salary on financial strain which reduces psychological strain. This is interesting as the prevailing wisdom is that having a salaried partner is likely to be protective and suggests that more research is needed to tease out the moderators and processes through which partner support works.

\section{Limitations and future research}

Our analyses are limited in two ways. We did not assess all possible situations or experiences during unemployment. Nor did we manipulate the situational variables, which is what is really needed to demonstrate mediation (Judd, Kenny, \& McClelland, 2001). Rather we relied on naturally occurring variations in managers' unemployment circumstances. In addition caution needs to be exercised in the interpretation of the results. Study 2 was cross-sectional and lacks the internal validity of a longitudinal study. Care needs to be taken in determining the direction of causality, particularly between the proposed mediators and the outcome (psychological strain), as there are likely to be feedback loops within the model. Surveys are also vulnerable to common method variance and spill-over between measures. However the careful development of the experiences-of-unemployment measures and the use of situational variables that cannot be attributed to reverse causality add weight to the conclusions. Finally some of the results are significant at the 0.10 level (two tailed), and need to be treated cautiously. In combination with the other results and the directional hypotheses we believe them to be meaningful and to provide a coherent picture of the mechanisms through which these situational variables affect psychological strain. Future researchers may want to examine the mediators more closely, incorporating emotion regulation strategies and the effects of these strategies on job search behavior and success. In addition it would be useful to explore specific interventions within a career transition program to develop effective coping strategies and to raise agency and self-efficacy to more fully tease out their relative importance and rule out reverse causality. Some work in this area has been done (Joseph \& Greenberg, 2001; Spera, Buhrfeind, \& Pennebaker, 1994) but these studies have generally focused on re-employment outcomes rather than reduced psychological strain.

\section{Implications for practice}

The research provides evidence of the utility of providing a 'golden parachute' to managers experiencing an involuntary termination, at least for the managers being terminated. There is a significant additive effect of career transition support and financial compensation in protecting managers from psychological strain during unemployment. In addition there is evidence that social resources, outside of the context of a career transition program, provide protection over and above the effects of the 'golden parachute'. This suggests that even if managers don't receive support from their former employers they can benefit from involvement in social activities within their community.

There is evidence that the important features of the career transition program are the enhanced sense of control or agency that the managers experience and the reduced negative emotions associated with loss. There is no evidence to suggest that it is the structuring of time that makes a difference. This suggests that programs should focus on managers gaining mastery and control of the environment and regulating emotions (both positive and negative).

\section{References}

Archer, J., \& Rhodes, V. (1995). A longitudinal study of job loss in relation to the grief process. Journal of Community E Applied Social Psychology, 5, 183-188.

Atkinson, T., Leim, R., \& Leim, J. H. (1986). The social costs of unemployment: Implications for social support. Journal of Health and Social Behavior, $27,317-331$.

Banks, M. H., Clegg, C. W., Jackson, P. R., Kemp, N. J., Stafford, E. M., \& Wall, T. D. (1980). The use of the general health questionnaire as an indicator of mental health in occupational studies. Journal of Occupational Psychology, 53, 187-194.

Benight, C. C., \& Bandura, A. (2004). Social cognitive theory of posttraumatic recovery: The role of perceived self-efficacy. Behaviour Research and Therapy, 42 , $1129-1148$.

Blau, G. (2008). Exploring antecedents of individual grieving stages during anticipated work site closure. Journal of Occupational and Organizational Psychology, 81, $529-550$.

Bolton, W., \& Oatley, K. (1987). A longitudinal study of social support and depression in unemployed men. Psychological Medicine, 17, 453-460.

Brewington, J. O., Nassar-McMillan, S. C., Flowers, C. P., \& Furr, S. R. (2004). A preliminary investigation of factors associated with job loss grief. The Career Development Quarterly, 53, 78-83.

Broadbent, D. E. (1971). Decision and stress. London: Academic Press.

Broman, C. L., Hamilton, V. L., Hoffman, W. S., \& Mavaddat, R. (1995). Race, gender, and the response to stress: Autoworkers vulnerability to long-term unemployment. American Journal of Community Psychology, 23, 813-842.

Cohen, S., \& Wills, T. A. (1985). Stress, social support and the buffering hypothesis. Psychological Bulletin, 98, 310-357.

Conger, J. A. (1998). Qualitative research as the cornerstone methodology for understanding leadership. The Leadership Quarterly, 9, 107-122.

Creed, P. A., Hicks, R. E., \& Machin, M. A. (1998). Behavioural plasticity and mental health outcomes for long-term unemployed attending occupational training programmes. Journal of Occupational and Organizational Psychology, 71, 171-191.

Creed, P. A., \& Klisch, J. (2005). Future outlook and financial strain: Testing the personal agency and latent deprivation models of unemployment and well-being. Journal of Occupational Health Psychology, 10, 251-260.

Feather, N. T., \& Bond, M. J. (1983). Time structure and purposeful activity among employed and unemployed university graduates. Journal of Occupational Psychology, 56, 241-254.

Fielden, S. L., \& Davidson, M. J. (2001). Stress and gender in unemployed female and male managers. Applied Psychology: An International Review, 50, 305-334. 
Fredrickson, B. L. (1998). What good are positive emotions? Review of General Psychology, 2, 300-319.

Fryer, D. (1986). Debate on unemployment: Employment deprivation and personal agency during unemployment. Social Behaviour, 1, 3-23.

Fryer, D., \& Fagan, R. (2003). Toward a critical community psychological perspective on unemployment and mental health research. American Journal of Community Psychology, 32, 89-96.

Fryer, D., \& McKenna, S. (1987). Redundant skills: Temporary unemployment and mental health. In M. Patrickson (Ed.), Readings in organisational behaviour (pp. 48-70). Sydney, Australia: Harper \& Row.

Fryer, D., \& Payne, R. (1986). Being unemployed: A review of the literature on the psychological experience of unemployment. In C. L. Cooper, \& I. T. Robertson (Eds.), International review of industrial and organizational psychology (pp. 235-278). Chichester, England: Wiley.

Glaser, B. G., \& Strauss, A. L. (1967). The discovery of grounded theory: Strategies for qualitative research. New York, NY: Aldine de Gruyter.

Goldberg, D. P. (1972). The detection of psychiatric illness by questionnaire. Oxford, England: Oxford University Press.

Gore, S. (1978). The effect of social support in moderating the health consequences of unemployment. Journal of Health and Social Behaviour, 19, 157-165.

Hartley, J. F. (1980). The impact of unemployment on the self esteem of managers. Journal of Occupational Psychology, 53, 147-155.

Hayes, A. F. (2009). Beyond Baron and Kenny: Statistical mediation analysis in the new millennium. Communication Monographs, 76, 408-420.

Henwood, K. L., \& Pidgeon, N. F. (1992). Qualitative research and psychological theorising. British Journal of Psychology, 83, 97-111.

Jackson, P. R. (1988). Personal networks, support mobilization and unemployment. Psychological Medicine, 18, 397-404.

Jackson, P. R., Stafford, E. M., Banks, M. H., \& Warr, P. B. (1983). Unemployment and psychological distress in young people: The moderating role of employment commitment. Journal of Applied Psychology, 68, 525-535.

Jahoda, M. (1982). Employment and unemployment. Cambridge, England: Cambridge University Press.

Joseph, L. M., \& Greenberg, M. A. (2001). The effects of a career transition program on reemployment success in laid off professionals. Consulting Psychology Journal: Practice and Research, 53, 169-181.

Judd, C. M., \& Kenny, D. A. (1981). Process analysis: Estimating mediation in treatment evaluations. Evaluation Review, 5, 602-619.

Judd, C. M., Kenny, D. A., \& McClelland, G. H. (2001). Estimating and testing mediation and moderation in within-subject designs. Psychological Methods, 6, $115-134$.

Karsten, I. P., \& Klaus, M. (2006). Incongruence as an explanation for the negative mental health effects of unemployment: Meta analytic evidence. Journal of Occupational and Organisational Psychology, 79, 595-621.

Kessler, R. C., Turner, J. B., \& House, J. S. (1988). Effects of unemployment on health in a community survey: Main, modifying, and mediating effects. Journal of Social Issues, 44, 69-85.

Kozlowski, S. W. J., Chao, G. T., Smith, E. M., \& Hedlund, J. (1993). Organizational downsizing: Strategies, interventions and research implications. In C. L. Cooper, \& I. T. Robertson (Eds.), International review of industrial and organizational psychology (pp. 264-332). Chichester, England: Wiley.

Latack, J. C., Kinicki, A. C., \& Prussia, G. E. (1995). An integrative process model of coping with job loss. Academy of Management Review, 20, 311-342.

Mackay, C. J., \& Cooper, C. L. (1987). Occupational stress and health: Some current issues. In C. L. Cooper, \& I. T. Robertson (Eds.), International review of industrial and organizational psychology (pp. 167-199). Chichester, England: Wiley.

Mallinckrodt, B., \& Bennett, J. (1992). Social support and the impact of job loss in dislocated blue collar workers. Journal of Counseling Psychology, 39, 482-489.

Mallinckrodt, B., \& Fretz, B. R. (1988). Social support and the impact of job loss on older professionals. Journal of Counseling Psychology, 35, 281-286.

McKee-Ryan, F., Song, Z., Wanberg, C. R., \& Kinicki, A. J. (2005). Psychological and physical well-being during unemployment: A meta-analytic study. Journal of Applied Psychology, 90, 53-76.

Murphy, G. C., \& Athanasou, J. A. (1999). The effect of unemployment on mental health. Journal of Occupational and Organizational Psychology, 72, 83-99.

Paul, K. I., \& Moser, K. (2009). Unemployment impairs mental health: Meta-analyses. Journal of Vocational Behavior, 74, $264-282$.

Preacher, K. J., \& Hayes, A. F. (2008). Asymptotic and resampling strategies for assessing and comparing indirect effects in multiple mediator models. Behavior Research Methods, 40, 879-891.

Price, R. H. (1992). Psychosocial impact of job loss on individuals and families. Current Directions in Psychological Science, 1, 9-11.

Price, R. H., Choi, J. N., \& Vinokur, A. D. (2002). Links in the chain of adversity following job loss: How financial strain and loss of personal control lead to depression, impaired functioning and poor health. Journal of Occupational Health Psychology, 7, 302-312.

Price, R. H., van Ryn, M., \& Vinokur, A. D. (1992). Impact of preventative job search intervention on the likelihood of depression among the unemployed. Journal of Health and Social Behavior, 33, 158-167.

Rantakeisu, U., \& Jonsson, L. R. (2003). Unemployment and mental health among white collar workers - A question of work involvement and financial situation. International Journal of Social Welfare, 12, 31-41.

Ratcliff, S. R., \& Bogdan, J. (1988). Unemployed women: When 'social support' is not supportive. Social Problems, 35, 54-63.

Rowley, K. M., \& Feather, N. T. (1987). The impact of unemployment in relation to age and length of unemployment. Journal of Occupational Psychology, 60, 323-332.

Spera, S. P., Buhrfeind, E. D., \& Pennebaker, J. W. (1994). Expressive writing and coping with job loss. Academy of Management Journal, $37,722-733$.

Starrin, B., \& Larson, G. (1987). Coping with unemployment: A contribution to the understanding of woman's unemployment. Social Science E Medicine, 25, $163-171$

Stokes, J., \& Levin, I. (1986). Gender differences in predicting loneliness from social network characteristics. Journal of Personality and Social Psychology, 51 , 1069-1074.

Vinokur, A. D., \& Schul, Y. (1997). Mastery and inoculation against setbacks as active ingredients in the JOBS intervention for the unemployed. Journal of Consulting and Clinical Psychology, 65, 867-877.

Vinokur, A. D., \& van Ryn, M. (1993). Social support and undermining in close relationships: Their independent effects on mental health of unemployed persons. Journal of Personality and Social Psychology, 65, 350-359.

Vuori, J., \& Silvonen, J. (2005). The benefits of a preventative job search program on re-employment and mental health at 2 year follow-up. Journal of Organisational and Occupational Psychology, 78, 43-52.

Warr, P. B. (2007). Work, happiness and unhappiness. Mahwah, NJ: Lawrence Erlbaum Ass.

Warr, P. B., \& Jackson, P. R. (1985). Factors influencing the psychological impact of prolonged unemployment and re-employment. Psychological Medicine, 15, 795-807.

Warr, P. B., Jackson, P. R., \& Banks, M. H. (1988). Unemployment and mental health: Some British studies. Journal of Social Issues, 44, 47-68.

Westman, M. (2001). Stress and strain crossover. Human Relations, 54, 717-751.

Winefield, A. H., Winefield, H. R., Tiggemann, M., \& Goldney, R. D. (1991). A longitudinal study of the psychological effects of unemployment and unsatisfactory employment on young adults. Journal of Applied Psychology, 76, 424-431.

Zikic, J., \& Klehe, U. (2006). Job loss as a blessing in disguise: The role of career exploration and career planning in predicting reemployment quality. Journal of Vocational Behavior, 69, 391-409. 